\title{
Enterprise Interoperability Maturity: A Model Using Fuzzy Metrics
}

\author{
Wided Guédria ${ }^{1,2}$, Yannick Naudet ${ }^{1}$, and David Chen ${ }^{2}$ \\ 1 CITI, Henri Tudor Public Research Center \\ 29, Avenue J.F. Kennedy, L-1855 Luxembourg-kirchberg \\ prenom.nom@tudor.lu, \\ 2 IMS/LAPS,Université Bordeaux 1, \\ 351, cours de la libération, 33405 Talence cedex \\ prenom.nom@ims-bordeaux.fr
}

\begin{abstract}
Measuring interoperability maturity allows a company to know its strengths and weaknesses in terms of interoperability with its current and potential partners, and to prioritize improvement actions. Existing maturity models however cover only few aspects of interoperability. This paper aims at presenting a Maturity Model for Enterprise Interoperability (MMEI) based on the Framework for Enterprise Interoperability currently under CEN/ISO standardization process. The proposed model takes into account the existing relevant maturity models and goes beyond, extending the coverage of the interoperability domain. Together with the MMEI, we provide an assessment framework which has the particularity to be based on Fuzzy sets theory. Both are demonstrated with an illustrative case study.
\end{abstract}

Keywords: Interoperability, Framework of Enterprise Interoperability, maturity model, maturity level, linguistic variable.

\section{Introduction}

In order to support enterprises to better interoperate with their partners, clients, providers, etc; enterprise interoperability requires to be assessed and continuously improved. Enterprise interoperability can be measured in two ways : $a$ priori where the measure relates to the potentiality of a system to be interoperable with a possible future partner whose identity is not known at the moment of evaluation; a posteriori where the measure relates to the compatibility measure between two (or more) known systems willing to interoperate. Today there exist many maturity models. Few were developed for interoperability assessment. The most known existing interoperability maturity models are: LISI (Levels of Information System Interoperability) [1, OIM (Organizational Interoperability Model) [2], LCIM (Levels of Conceptual Interoperability Model) [3], and EIMM (Enterprise Interoperability Maturity Model) 4]. In most of cases, these models focus on one simple facet of interoperability (data, technology, conceptual, Enterprise modeling, etc.), while sometimes also developing in a superficial manner

C. Salinesi and O. Pastor (Eds.): CAiSE 2011 Workshops, LNBIP 83, pp. 69-80, 2011.

(C) Springer-Verlag Berlin Heidelberg 2011 
other facets [10]. Measuring more than one facet of interoperability implies using multiple maturity models. This creates redundancies and incompatibilities and makes the aggregation process more difficult. The objective of this paper is to present the Maturity Model for Enterprise Interopeability (MMEI) and its methodologies. MMEI is based on existing relevant maturity models and it extends existing works to cover all main aspects and dimensions of enterprise interoperability. In particular MMEI focus on the a priori interoperability measurement and is built using the Framework for Enterprise Interoperability (FEI) [7. As part of the MMEI assessment process, allowing to determine the maturity of an enterprise in terms of interoperability, we introduce an innovative method which relies on the Fuzzy Sets theory 5]. In fuzzy logic applications, non-numerical linguistic variables are often used to facilitate the expression of rules and facts. Traditional methods of assessment are based on assessor's judgment which is subjective and can be source of incomplete information, interpersonal contradictions, etc. Moreover employees of the evaluated enterprise reply to questions using their own words and interpretations. To facilitate the use of the collected information from human sources and to lower biases due to human judgment, we propose the use of linguistic variables. The maturity level is then obtained by aggregating the assessment results according to a suitable operator. In our case, we use the Ordered Weighted Average (OWA) operator [14]. The paper is structured as follows. In section 2, the FEI is briefly presented. Then, MMEI is outlined in section 3. In section 4, the basis of the assessment framework and associated metrics are exposed and an illustrative example is presented. Finally section 5 concludes the paper and proposes future work.

\section{Preliminaries}

Generally speaking, interoperability is the ability of two or more systems or components to exchange information and to use the information that has been exchanged [6]. When this ability is not achieved, interoperability becomes a problem that must be solved.

Solutions to interoperability problems can be characterized according to interoperability approaches defined in [11] and both solutions and problems can be localized into enterprises levels and characterized by interoperability levels, as defined in the Framework for Enterprise Interoperability (FEI). FEI has been initially elaborated in INTEROP NoE [7] and is now under development within the $\mathrm{CEN} / \mathrm{ISO}$ standardization process (CEN/ISO 11354). It defines a classification scheme for interoperability knowledge according to three dimensions:

- Interoperability concerns, defining the content of interoperation that may take place at various levels of the enterprise (data, service, process, business).

- Interoperability barriers, identifying various obstacles to interoperability in three categories (conceptual, technological, and organizational)

- Interoperability approaches, representing the different ways in which barriers can be removed (integrated, unified, and federated) 
The first two dimensions, interoperability concerns and barriers, constitute the problem space of enterprise interoperability. The intersection of a barrier and a concern is the set of interoperability problems having the same barrier and concern. The three dimensions together constitute the solution space of enterprise interoperability. FEI is used as a basis to build MMEI, but has been slightly changed. We use the term "interoperability level" instead of "interoperability barrier". Indeed, by having an a priori approach of interoperability measurement, MMEI does not deal with removing barriers but it allows an enterprise to be prepared to interoperability through the respect of defined practices. Moreover the cited dimensions (conceptual, technological and organizational) can also be used to characterize interoperability solutions. They are, obviously, specific for interoperability domain and related to aspects or facets of interoperability [12. Furthermore, Interoperability concerns is specific to the enterprise domain so we should use the term "enterprise interoperability concern". However, for a matter of simplicity, we use the term "enterprise concerns". The development of the MMEI is a long and iterative process which needs significant industrial applications and case-studies for its improvement and validation. The model presented here is an evolution of a preliminary version presented in [10, 9] and it is currently being discussed in the ISO TC184 SC5 Working Group.

\section{MMEI Model}

When an enterprise wants or needs to work or collaborate with other enterprises, different tools such as guidelines or metrics might be useful in order to ensure proper interoperation at all levels of the enterprise system. The idea of our research is to propose a Maturity Model for Enterprise Interoperability (MMEI) allowing companies to evaluate their interoperability potentiality in order to know the probability that they have to support efficient interoperation and to detect precisely the weaknesses that are sources of interoperability problems. In this section we present an overview of the MMEI model with a brief description of its levels. The complete description of the model can be found in 9 .

The proposed model differs from all other maturity models dedicated to interoperability so far. It is intended to cover the three interoperability levels (conceptual, technological, organizational) which are used to classify the barriers in FEI, at each of the enterprise interoperability concerns (business, process, service, data). MMEI defines five levels of interoperability maturity as presented in table 1.

Each one of the cited levels is described based on a simplified version of the interoperability framework that contains only two basic dimensions "interoperability levels" and "enterprise concerns" as shown in figure 1.

The intersection between the two dimensions is described as states or qualities that should have the assessed enterprise and best practices to be considered at each level. Best practices are tasks and activities that when put in place, allow reaching a targeted level of interoperability maturity. In order to have a 
Table 1. Overview of MMEI levels

\begin{tabular}{|c|c|c|c|c|c|c|}
\hline \multirow{2}{*}{\multicolumn{2}{|c|}{$\frac{\text { Maturity Level }}{\text { Level } 4 \text { - Adapted }}$}} & \multicolumn{5}{|c|}{ Maturity Capability } \\
\hline & & \multicolumn{5}{|c|}{$\begin{array}{l}\text { Capable of negotiating and dynamically accommodating } \\
\text { with any heterogeneous partner }\end{array}$} \\
\hline \multicolumn{2}{|c|}{ Level 3 - Organized } & \multicolumn{5}{|c|}{$\begin{array}{l}\text { Capable of meta modeling to achieve the mappings needed } \\
\text { to interoperate with multiple heterogeneous partners }\end{array}$} \\
\hline \multicolumn{2}{|c|}{ Level 2 - Aligned } & \multicolumn{5}{|c|}{$\begin{array}{l}\text { Capable of making necessary changes to align to common } \\
\text { formats or standards }\end{array}$} \\
\hline \multicolumn{2}{|c|}{ Level 1 - Defined } & \multicolumn{5}{|c|}{$\begin{array}{l}\text { Capability of properly modeling and describing systems to } \\
\text { prepare interoperability }\end{array}$} \\
\hline \multicolumn{2}{|c|}{ Level 0 - Isolated } & \multicolumn{5}{|c|}{ Not relevant: there is no capability for interoperation } \\
\hline \multirow{7}{*}{ 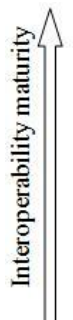 } & Level 4 : Adapted & \multirow{5}{*}{$\begin{array}{l}\text { Enterprise } \\
\text { concerns }\end{array}$} & & \multicolumn{3}{|c|}{ Interoperability Level } \\
\hline & & & & Conceptual & Technological & Organizational \\
\hline & Level 3 : Organized & & Business & & & \\
\hline & & & Process & & & \\
\hline & Level 2: Aligned & & Service & & & \\
\hline & Level 1 : Defined & & Data & & & \\
\hline & Level $0:$ Isolated & & & & & \\
\hline
\end{tabular}

Fig. 1. Zoom on MMEI level

clearer idea of the description of a maturity level and the way that best practices are presented, we provide in Table 2 the description of the MMEI level 2.

A possible graphical representation of interoperability maturity using MMEI is a camembert form divided into three parts (see Figure 2). Each part stands for an assessed interoperability level: conceptual, technological or organizational. In each part, arrows represent enterprise concerns : business, process, data and service. The arrows are graduated to present the maturity level: $1,2,3$ or 4 . Figure 2 illustrates a case where the assessed enterprise is at the level 3 regarding the conceptual interoperability, level 2 regarding technological interoperability and the level 4 regarding organizational interoperability.

\section{MMEI Assessment}

The assessment is an activity that can be performed either as part of an improvement initiative or as part of a maturity determination approach. In this 
Table 2. Description of the MMEI level 2

\begin{tabular}{|c|c|c|c|}
\hline & Conceptual & Technological & Organizational \\
\hline Business & $\begin{array}{l}\text { Use of standards to } \\
\text { facilitate the alignment } \\
\text { with other Business } \\
\text { models }\end{array}$ & $\begin{array}{l}\text { Use of standards to fa- } \\
\text { cilitate the alignment } \\
\text { with other IT infras- } \\
\text { tructures / platforms }\end{array}$ & $\begin{array}{l}\text { Adjustable } \\
\text { rules }\end{array}$ \\
\hline Process & $\begin{array}{l}\text { Use of standards to } \\
\text { facilitate the alignment } \\
\text { with other process } \\
\text { models }\end{array}$ & $\begin{array}{l}\text { Platform process exe- } \\
\text { cution tools using stan- } \\
\text { dards }\end{array}$ & $\begin{array}{l}\text { Procedures of work de- } \\
\text { fined and adjustable }\end{array}$ \\
\hline Service & $\begin{array}{l}\text { Use of standards to fa- } \\
\text { cilitate the alignment } \\
\text { with other service mod- } \\
\text { els }\end{array}$ & $\begin{array}{l}\text { Use of standards to fa- } \\
\text { cilitate the alignment } \\
\text { with other platforms } \\
\text { Service execution }\end{array}$ & $\begin{array}{l}\text { Guidelines for service } \\
\text { exchanges in place and } \\
\text { can be adjusted }\end{array}$ \\
\hline Data & $\begin{array}{l}\text { Use of standards to fa- } \\
\text { cilitate the alignment } \\
\text { with other data models }\end{array}$ & $\begin{array}{l}\text { Data bases con- } \\
\text { nectable, remote access } \\
\text { to data base possible }\end{array}$ & $\begin{array}{l}\text { Rules and methods for } \\
\text { data interoperability } \\
\text { management in place } \\
\text { and can be adjusted }\end{array}$ \\
\hline
\end{tabular}

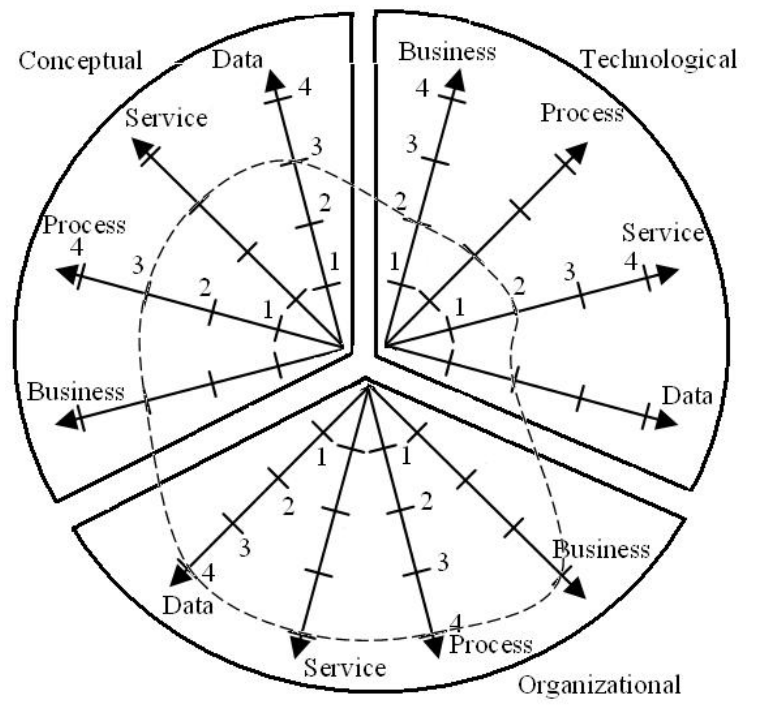

Fig. 2. Graphical representation of an MMEI application example 
part, we present the different stages of the assessment process and the associated methodologies to determine the enterprise interoperability maturity level.

\subsection{MMEI Assessment Stages}

The first step when conducting an assessment process is to define the purpose of the assessment, its scope, under which constraints it is done (i.e., the context) and any additional information that needs to be gathered. Assessors may originate from the organization, be external to the organization or a combination of both.

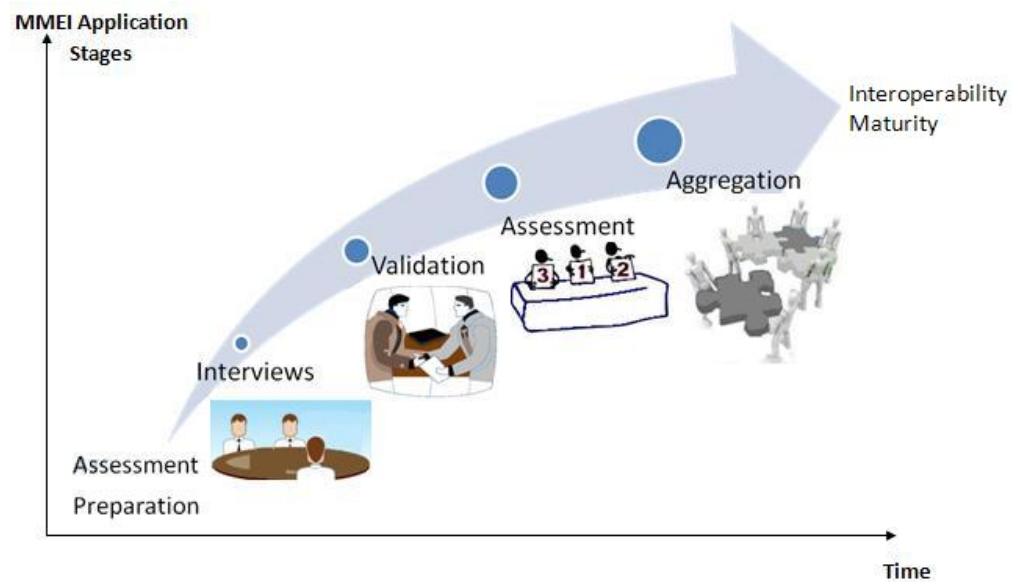

Fig. 3. Membership diagrams of the linguistic variables

They need to collect information through a series of interviews. The content of the assessment interview depends on the assessment scope and the enterprise needs. From the interviews, a rating shall be assigned based on validated data. Actions are taken to ensure that the data is accurate and sufficiently covers the assessment scope, including seeking information from independent sources; using past assessment results; and holding feedback sessions to validate the information collected. A quick synthesis on the interview and conclusion is finally performed by the assessor team. A value is associated to each practice, based on what should be done according to the maturity model. It is assigned based on assessors' judgment about the achievement degree of considered practices. Such judgment is subjective and can be source of incomplete information, interpersonal contradictions, etc. Moreover employees of the evaluated enterprise will reply to questions using their own words and not with numerical degrees to quantify a task achievement. To facilitate the mapping between collected information from human sources and the global evaluation of a maturity level, we propose to use linguistic values (like e.g. "achieved" practice, "partially achieved" practice), etc.) and to exploit the Fuzzy 
sets theory. The obtained values are then aggregated allowing to determine the interoperabiliy maturity level of the enterprise under assessment. An overview of the assessment process is given by the figure 3 .

\subsection{Linguistic Variable}

Definition 1. A linguistic variable is a variable whose associated values are linguistic rather than numerical. Each linguistic variable is characterized by the set:

$(x, T(x), U, G, M)$, where: $x$ is the variable name, $T(x)$ is the set of linguistic values that may take $x, U$ is the universe of discourse representing the whole repository that contains all the elements linked to the given context, $G$ is the syntactic rule to generate linguistic values of $x, M$ is the semantic rule for associating a meaning to each linguistic value [5].

Consider the linguistic variable $x=$ "state of the best practice"; $x$ can be defined with the set of terms: $T(x)=$ (Not Achieved (NA), Partially Achieved (PA), Achieved (A), Fully Achieved (FA)), which form the universe of discourse $X=$ $[0 \%, 100 \%]$. We characterize both levels of maturity and practices achievements using variables associated to $T(x)$. Each one is respectively represented by a membership function (c.f. figure 4$)$.

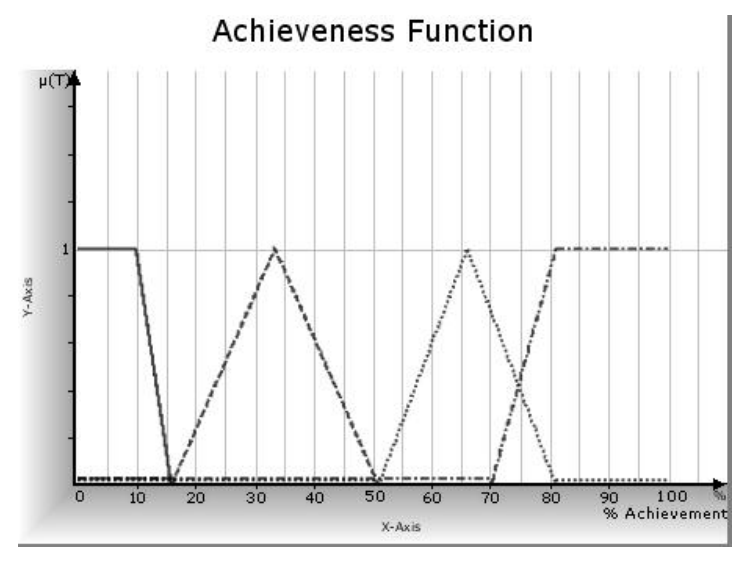

Fig. 4. Membership diagrams of the linguistic variables

In the enterprise context, multiple information sources having different knowledge level can be exploited during an evaluation. Assessors need to aggregate linguistic values issued from these sources in order to determine the achievement degree of needed practices and thus the enterprise level. To obtain directly an aggregated value, we use the Ordered Weighted Average (OWA) operator [14]. In addition to systematize the aggregation process, it has the main advantage 
to allow obtaining a value that reflects the opinion of the assessors taking into account all the scores affected to the evaluated practices. From the obtained aggregation, we can determine if a level is fulfilled or not. A level is reached if it is at least $\mathrm{A}$ and the preceding level is reached with FA.

\subsection{Linguistic Variable and OWA Operators}

The $O W A$ operator was introduced in [13. It is an aggregation technique based on the ordered weighted averaging operator.

Definition 2. An $O W A$ operator of dimension $n$ is a mapping $O W A: R^{n} \rightarrow R$ that has an associated $n$ vector : $w=\left(w_{1}, w_{2}, \ldots w_{n}\right)$

such as $w_{j} \in[0,1], 1 \leq j \leq n$ and $\sum_{j=1}^{n} w_{j}=w_{1}+w_{2}+\ldots+w_{n}=1$ furthermore

$$
O W A\left(a_{1}, a_{2}, \ldots a_{n}\right)=\sum_{j=1}^{n} w_{j} b_{j}=w_{1} b_{1}+\ldots+w_{n} b_{n}
$$

where $b_{j}$ is the $j$ - th largest element of the bag $\left(a_{1}, \ldots a_{n}\right.$.

Definition 3. Let $a_{1}, a_{2}, \ldots, a_{n}$ be a collection of arguments, and let $A$ be the average value of these arguments: $A=\frac{1}{n} \sum_{j=1}^{n} a_{j}$, then :

$$
s\left(b_{j}, A\right)=1-\frac{\left|b_{j}-A\right|}{\sum_{j=1}^{n}\left|a_{j}-A\right|}, j=1,2, \ldots, n
$$

is called the similarity degree of the $j$-th largest argument $b_{j}$ and the average value $A$.

Definition 4. Let the $w=\left(w_{1}, w_{2}, \ldots, w_{n}\right)$ be the weight vector of the $O W A$ operator, then we define the following:

$$
w_{j}=\frac{s\left(b_{j}, A\right)}{\sum_{j=1}^{n} s\left(b_{j}, A\right)} ; j=1,2, \ldots, n,
$$

\subsection{Illustrative Example}

To illustrate the use of the maturity model and its metrics, we present in this section an illustrative example that is inspired from a case study proposed by the Network of Excellence INTEROP [8]. The company modeled is part of a group of companies, which is specialized in telecommunications, production and distribution of batteries, as well as mobile phones.

To distribute its products and services, the company retail sales to two kinds of distributors: franchisees, who are distributors in exclusive contract with the company and may only offer its products and services; and independent dealers, who may have contracts with other companies. A franchisee must use the same tools as the company; therefore, interoperability issues in this case are irrelevant for our study. However, with independent dealers, the interoperability subject can be tackled. 
There are 5 main departments in the company: Commercial, Sales, Financial, Logistics and IT. IT department is responsible for system administration, imports and exports of data in different databases and creating specific reports needed by the other departments. The products distribution is based on the rule of proportionality: If the total quantity of ordered products is available, all orders are fulfilled. Otherwise, the company decides what quantities to be allocated based on the proportionality between the quantity of products available and the quantity ordered by retailers. According to this rule, it adjusts its orders and publishes the bills that are sent to corresponding retailers for payment. Upon receipt of invoice, retailers emit a debit authorization for the sales department. This work procedure is well known by the company staff, it is successful and the Enterprise is able to adjust it when needed. Exchanged data between partners are of three types. (1) Orders from the retailer to the company (2) Invoices from the company to its retailer and, (3) Levy authorization from the retailer to the company.

Currently the company headquarters and branches work with a decentralized database and there is a daily transfer of information from the shops to the headquarters and back. The goal of the enterprise is to investigate its interoperability potential in order to anticipate future interoperability operations. According to the preparations made, the company aims to reach Level 2 of potential interoperability. According to the given information, we make an assessment of the Organizational Interoperability. After a series of interviews, the assessors provide the evaluation sheet shown by table 3 where B stands for Business, $\mathrm{P}$ stands for Process, S stands for Service and D stands for Data.

This evaluation consists in combining the assessors ratings for each practice in order to determine the interoperability maturity level. Using the achieve-

Table 3. Evaluation sheet for potential interoperability

\begin{tabular}{|c|c|c|c|c|}
\hline & Practices to Evaluate & Findings & $\begin{array}{l}\text { Team } \\
\text { ing }\end{array}$ & Rat- \\
\hline Business & Adjust business rules & $\begin{array}{l}\text { Business is adjusted ac- } \\
\text { cording to the propor- } \\
\text { tionality rule }\end{array}$ & $90 \%$ & \\
\hline Process & $\begin{array}{l}\text { Procedures of work and } \\
\text { guidelines are defined }\end{array}$ & yes & $85 \%$ & \\
\hline Service & $\begin{array}{l}\text { Adjustable procedures } \\
\text { of work }\end{array}$ & $\begin{array}{l}\text { Procedures can be ad- } \\
\text { justed if needed }\end{array}$ & $80 \%$ & \\
\hline Data & $\begin{array}{l}\text { Rules for data interop- } \\
\text { erability are in place }\end{array}$ & Daily transfer of data & $70 \%$ & \\
\hline
\end{tabular}




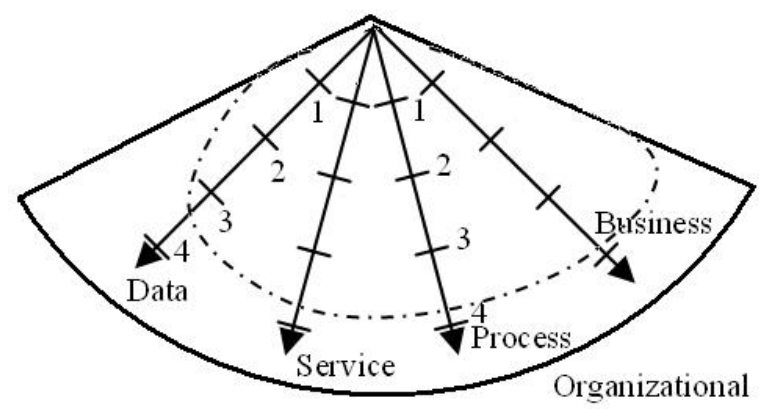

Fig. 5. Zoom on the MMEI organizational interoperability maturity of the use case

ment functions (see fig.4), assessors can provide either a linguistic variable or a percentage value corresponding to the practice achievement. For the sake of simplicity, we use the percentage rating. According to table 3, we have the following ratings : $a_{1}=90, a_{2}=85, a_{3}=80, a_{4}=70$.

Therefore, the re-ordered arguments $a_{j}: j=1,2,3,4$ in descending order are: $b_{1}=90, b_{2}=85, b_{3}=80, b_{4}=70$.

Using eq.(2) and eq. (3), we find : $w_{1}=0.35, w_{2}=0.15, w_{3}=0.05, w_{4}=0.45$. By eq. (1), the aggregated rating argument is computed as:

OWA $\left(a_{1}, a_{2}, a_{3}, a_{4}\right)=79.75$

Using the membership functions we have defined for our variables (here maturity level),(see fig.4), we find that,all practices are "Fully Achieved" and the level 2 of organizational interoperability level is fully reached. Figure 5 shows a graphical representation of this example.

\subsection{Discussion}

MMEI proposes an innovative approach for interoperability assessment. It allows to have an automatic aggregation of the affected scores. Here, we haven't presented the aggregation of the individual assessors allowing to have the global evaluation sheet. This step is done by an iterative application of the OWA operator. Semantically, OWA allows to relieve the influence of unfair arguments on the aggregated results. It assigns low weights to the extreme scores which are considered as "false" or "biased" ones, that is to say, the closer a value to the average value $\mathrm{A}$, the more the weight is. This method has advantages and drawbacks. In fact, it allows to take into account the most of the assessors opinions and to find a consensus. However, we have no idea about the characteristics and expertise of the evaluators which can be the cause of biased results. A possible solution is to give more importance to the evaluations of true experts and to multiply the OWA weights with a confidence coefficient based on a self-evaluation of the assessors and the history of their assessment qualities. 


\section{Conclusion}

In this paper, we have presented a maturity model for enterprise interoperability (MMEI). MMEI proposes an innovative approach for interoperability assessment which uses the OWA aggregation operator. The latter allows a positive compensation between the assigned ratings, in order to find a trade-off between the enterprise assessors. The idea behind this is to find the global evaluation between the worst and the best ratings. MMEI covers other approaches in terms of measurement and deals with the potential interoperability assessment which is not addressed by existing ones. Future work is planned to refine the proposed model and metrics in order to take into account the individual expertise of the assessors in the aggregated ratings, and to perform some more detailed case studies in enterprises. A detailed questionnaire associated with a structured methodology will also be elaborated to support the use of MMEI in industry.

\section{Acknowledgment}

This work has been performed under the PhD grant TR-PhD-BFR07 funded by the Luxembourg National Research Fund (FNR).

\section{References}

1. C4ISR Interoperability Working Group.: Levels of Information Systems Interoperability (LISI). US Department of Defense (1998)

2. Clark, T., Jones, R.: Organizational interoperability maturity model for c2. In: Command and Control Research and Technology Symposium, Washington (1999)

3. Tolk, A., Muguira, J.: The levels of conceptual interoperability model. In: Fall Simulation Interoperability Workshop (2003)

4. ATHENA.: Advanced Technologies for Interoperability of Heterogeneous Enterprise Networks and their Applications, FP6-2002-IST1, Integrated Project Proposal (2003)

5. Zadeh, L.A.: Soft computing and Fuzzy logic. IEEE Software (1994)

6. IEEE (Institute of Electrical and Electronics Engineers).: Standard computer dictionary: A compilation of IEEE standard computer glossaries (1990)

7. Chen, D., Dassisti, M., Elvester, B.: Deliverable Interop DI.2. Enterprise Interoperability-Framework and knowledge corpus-Advanced report (2006)

8. Chen, D., Dassisti, M., Elvester, B.: Interop NOE deliverable di.3: Enterprise interoperability framework and knowledge corpus - final report. Technical report, Interoperability Research for Networked Enterprises Applications and Software (INTEROPNetwork of Excellence), IST - Contract no. IST-508 011 (2007)

9. Guédria, W., Chen, D., Naudet, Y.: A Maturity Model for Enterprise Interoperability. In: On the Move to Meaningful Internet Systems: OTM Workshops (2009)

10. Guédria, W., Naudet, Y., Chen, D.: Interoperability Maturity Models - Survey and Comparison. In: On the Move to Meaningful Internet Systems: OTM Workshops (2008) 
11. ISO 14258.: Industrial Atomation Systems - Concepts and Rules for Enterprise Models, ISO TC184/SC5/WG1 (1999)

12. Naudet, N., Latour, T., Guédria, W., Chen, D.: Towards a Systemic Formalisation of Interoperability. Computers in Industry, Special Issue on Integration and Information in Networked Enterprises (61/2) (2010)

13. Yager, R.R.: On ordered weighted averaging aggregation operators in multi-criteria decision making. IEEE Transactions on Systems, Man and Cybernetics 18, 183-190 (1988)

14. Yager, R.R.: Families of OWA operators. Fuzzy Sets and Systems 59, 125-148 (1993)

15. Yager, R.R.: Aggregation operators and fuzzy systems modeling. Fuzzy Sets and Systems 67, 129-145 (1994) 